Spatial Demography 2013 1(1): 111-119

http://spatialdemography.org

OPEN ACCESS

via Creative Commons 3.0
SPATIAL

DEMOGRAPHY

ISSN 2164-7070 (online)

\title{
COLUMN
}

\section{Conversation with Frank M. Howell}

\author{
Paul R. Voss \\ Editor, Teaching \& Learning
}

Editorial note: My assignment with Spatial Demography focuses on teaching and learning this subject matter. The changing face of this specialization makes course design, content, and pedagogy challenging. My column will address some of these issues. I will begin with a series of "conversations" with practicing spatial demographers, since we may learn a great deal from those who have already delved into teaching this material. I have structured this into a set of questions by me $(P R V)$ and responses from the person interviewed. This time it is Frank Howell $(F M H)$.

$P R V$ : Frank, you've been teaching and working with students in the area of spatial demography for many years. When did you first become involved in this field and what sparked your initial interest?

FMH: I began teaching a course using spatial methods in 1996 at Mississippi State in the Department of Sociology. It was sponsored by a software grant from ESRI to the tune of some $\$ 300,000$ (street value) of GIS software. I just thought it was time to introduce it into the graduate curriculum given the growth in the technology and the social nature of much demographic data.

However, I actually began learning GIS in 1983 while Associate Director of a social science computing lab at N.C. State. I was the founding
Sociology Editor of the journal Social Science Computer Review (Sage) and the PC mapping software package Atlas*Graphics arrived for a review by the journal. The editor, Dave Garson (still Editor!), asked me to take a look and I did. I actually became an advisor to Steven Poizner, President of Strategic Location Planning, because of my testing and suggestions for improvement. Steve had a real commitment to using spatial data in urban planning and I had one for using high technology in social research. That led me to dive headfirst into learning what I could about GIS and, as a result, am mostly self-taught through reading the works of others for the past three decades.

As a graduate student, I took a course called the History of Rural Sociology, taught by my advisor, Ray Sollie, who passed away last year. Ray was a long-time Extension Service appointee in community development so he knew the importance of understanding what Experiment Stations did. One semester-length assignment was to review the entire history of a single Experiment Station's research bulletins in rural sociology and prepare a summary of their major accomplishments as expressed through their Bulletin series. I happened to choose Wisconsin. Reading Galpin's 1915 bulletin on the social anatomy of a rural community in which he pioneered the use of hand-produced maps was something I had not forgotten. So when the GIS revolution started, this undertaking came back to me in spades. That, and being a student in Harold 
Kaufman's last graduate seminar, where I got a heavy dose of the Kaufman-Wilkinson "field theory" of community identification, gave me a great background to see the utility of understanding Geographic Information Systems from every facet.

$P R V: \quad$ That's very interesting but very GISfocused. From your perspective, how has the scope of spatial demography and the special role of GIS changed since you first became involved with the field?

FMH: When I petitioned the Departmental Courses \& Curriculum Committee about offering a special topics course titled "Spatial Analysis of Social Data," I was met with mostly dumbfounded faces. My good friend and colleague, Xiaohe Xu (now at UT-San Antonio), who also taught graduate statistics courses with me, finally stated what he felt was obvious: "But that's not sociology!". Xiaohe was correct, of course, at that time (1996). My reply was: "But neither was chi squared when Karl Pearson introduced it and now we teach it to undergraduate majors!”. I was allowed to offer the course on an experimental basis at first. It was filled with 30 seats, including someone on campus temporarily from the Jet Propulsion Laboratory in California. While I do not know for sure, it may have been one of the first such courses taught in a Sociology Department by that date.

The issues then were getting good locational data into a technical form, matching them with attribute data (the stuff we have always used), and performing some displays and analysis that gave some results that were useful. It was about like the old days of path analysis before the Alwin \& Hauser paper in ASR (1975) showed simple ways to automate (e.g., the computer does the hard work) the computation of direct and indirect effects. At that time, doing something statistical with spatial data was still fairly rare in sociology. Luc Anselin's early software in a run-time Gauss environment had not reached may of us then. Moreover, the Land-Deane approach was also not terribly widespread. My arguments to students then was that the challenge was to "put numbers back on the maps" because maps could be interpreted in various ways with equal apparent weight.

Since then, of course, we've moved substantially forward in the social sciences, including demography. We have fairly conventional data formats (e.g., the ESRI shapefile) for software interchangeability; most Federal and many State agencies publish spatial data; most research Universities have campus or state-wide site licenses for ESRI software; and there is a solid growth in free and open-source software for spatial analysis (e.g., QGIS, OpenGeoda). I will say that due to my administrative role in a $\$ 60 \mathrm{M}$ effort between the State of Mississippi and NASA to grow the commercial sector of remote sensing, we were able to get the first state-wide site license for ESRI software in the country. One of my students (Greg Works) went out to San Diego to receive one of ESRI's industry awards for contributions to GIS because of the model I designed to administer those software licenses. To do this, I had to become the state college board's software administrator working with the state Attorney General's Office. I learned a great deal about large organizational behavior and software licensing issues.

Now, we find that such software is commonplace in large research universities as well as many smaller ones who benefit from statewide software licensing. Free software fills in the gap fairly readily when commercial varieties are not readily available. Federal, state, and local government agencies tend to have some or most of their agency data available in GIS formats, although some seek cost-recovery for certain data elements (land parcel data, in particular). Statistical methods for spatial analysis have flourished, due partly to the leadership that Luc Anselin and his associates, Mike Goodchild and his colleagues, and a few others have exhibited in getting the NSF and USDA to fund research and development efforts. The open source community has made it's impact felt in this arena as well.

Students interested in spatial demography today will find many ruts already plowed in this garden. But there are many more left to be made. It is 
truly an exciting time with space for intellectual growth to those who wish to participate.

$P R V$ : You've mentioned several influential individuals in the development of your career. Who have been some of the other key influences in your professional life? Any former teachers or colleagues who have helped focus your interest in spatial demography?

FMH: As I reflect on this, Paul, two sets come to mind: those I did not have direct contact with and those with whom I did. I'll explain.

I came to graduate school fresh from being a News Director at a small radio station that I'd helped build in Milledgeville, GA (WXLX-AM). My gestalt was critical qualitative: my reporter's notepad was my "laboratory". Inequality and race relations were more exciting than, say, designing antennas for Westinghouse through understanding the physics of wave propagation (see below). The University of Wisconsin was the leading source of new knowledge and approaches to studying inequality during the 1970s. I read everything that I could get my hands on that any of those key faculty wrote and loved to meet some of them at professional conferences. I had to become competent in quantitative methods which led me to minor in statistics and teach in that department while writing my dissertation. My graduate advisor, Ray Sollie, egged me on and kept support funds for me to do that and to publish some modest papers along the way.

A temporary faculty member, Phil Kuhn, was there from the Census Bureau filling in for a professor on a two-year leave in the Middle East. Phil was a Leo Schnore student who taught a standard Shyrock \& Siegel demographic methods course. He was a splendid teacher who led me to better understand many of the tools and central concepts in demography over those two years. Phil's pragmatic side led him to later work for the Corps of Engineers in Vicksburg, MS, modeling boat and barge traffic for all of the Mississippi River using many of those same methods.

A contemporary of mine in graduate school, though at the University of Georgia, was Charles
Tolbert. We were both supported through an Experiment Station Regional Research Project focusing on status attainment during much of our graduate school years. Charlie did pioneering work on industrial organization, labor market structure, and computer applications in the social sciences. Charlie's work was, and is, first-rate. He's had a significant influence on my development regarding the blending of traditional demography with individual data.

Otis Dudley Duncan was a mesmerizing influence on me. His work was serious and reflected the self-criticism that good science should have. I read most all of his work, especially things that related to what he called statistical geography. One of his mentors, William F, Ogburn, was a native of my home state of Georgia. I read much of his work as an undergraduate at Georgia College since he was from about 60 miles from there. His writing and thought processes made a clear impression on me.

Finally, my graduate students have always taught me a great deal, even if only through the questions they asked. I always used a team approach with my advisees so I was only one of the group. A few of them include Feinian Chen, Paul Vowell (deceased), Greg Works, Lei Chen, Todd Mathews, and, of course, Jeremy Porter. I'm sure I learned as much from them as they did from me.

$P R V$ : It's interesting to me that you mention the infrequently-cited Duncan, Cuzzort and Duncan book on statistical geography (1961). I have always found it amazing how this book presaged so many of the core spatial concepts we now hold as foundational. What are some of the central concepts you feel absolutely must be included in a comprehensive semester-long course in spatial demography?

$F M H$ : For a long time, the term space had many different faces, at least in sociology. Getting students to visualize space in specific ways is paramount. I've taught key concepts in two phases. First, understanding what makes data elements spatial so that points, lines, or polygon attributes are understood as well as raster (cell) 
data. And, that they can be visualized as multiple "layers" in a spatial context. This is usually a key "aha!" moment for most students who have only been exposed to social survey (a-spatial) data. Second, many spatial concepts are reflexive. That is, a neighbor is only definable relative to another point, for example. Concepts of distance, adjacency, contiguity, interaction, and neighborhood are basic conceptual building blocks. Some methodological concepts that build and expand upon these include geo-referencing, spatial aggregation, buffers, clipping, unions, intersections, dissolves, spatial joins, network operations, point-in-polygon, spider diagrams, and nearest neighbors. Taking these ideas and extending them into spatial association is a critical jump for undergraduates (that is, does the map that looks so cool reflect randomness or some spatial pattern?) A student who completes a course having mastered these concepts will be ready to move forward in spatial demography.

$P R V: \quad$ I believe you have taught spatial demography both at the undergraduate and graduate levels. How do courses at these two levels differ? Is there a strong role for spatial demography in an undergraduate curriculum?

FMH: Paul, this is controversial but I do believe that both levels have a place. One key approach to the undergraduate course: never tell them that anything is "hard". Undergraduates can play well over their intellectual heads if we let them! While it may seem pandering to some, the tools that undergraduates who excel in a course on spatial demography learn have clear and demonstrable skills attractive in the labor market. One of my former student assistants who took my course is the current GPS architect at RIM (Blackberry) in Canada now. His first job was programming crop dusters (airplanes) to spray controlled amounts on customer's fields to both save money and to keep over-spraying down for environmental reasons. While he is exceptional, I think the difference is that the undergraduate course can make the most impact by being a bit more tooloriented. The graduate-level course should be far richer in substantive theory as well as more sophisticated methods and techniques.
$P R V$ : Do you use a textbook when teaching spatial demography? Are there certain textbooks of which you are particularly fond?

FMH: I've used several But no one single text really fits the bill for my taste. Much of this can be found on my course outline published on the CSISS website (just search for SO8243). As you know, one of your last Ph.D. advisees, Dr. Guangqing Chi, now teaches that course at Mississippi State.

For a single text for undergraduates, the one by Steven J. Steinberg \& Sheila L. Steinberg. 2006. Geographical Information Systems for the Social Sciences: Investigating Time and Place is a good and general one. Although now dated a bit, I would add Jay Lee \& David W.S. Wong. 2001. Statistical Analysis with ArcView GIS and ArcGIS. In combination, these two give a good coverage to the methods needed at the undergraduate level. However, it leaves substantive theory hanging out there for the instructor to introduce. I tended to do this through supplemental journal articles and examples I used in lectures along with follow-up homework, often just to replicate my lecture results. Your paper in PRPR (2007) on spatial demography was one of those after it appeared.

For graduate students, the landmark Michael F. Goodchild \& Donald G. Janelle (eds.). 2004. Spatially Integrated Social Science. Oxford University Press was a requirement as was Diana Liverman et al. (editors), People and Pixels: Linking Remote Sensing and Social Science (Washington, DC: National Academy Press).

Depending on the semester, I've also used these as texts:

Alan Peters \& Heather MacDonald. 2004. Unlocking the Census with GIS. ESRI Press.

A. Stewart Fotheringham, Chris Brunsdon, and Martin Charlton. 2002. Geographically Weighted Regression: The Analysis of Spatially Varying Relationships. Wiley.

Bruce Ralston. 2004. GIS and Public Data. 
Onword/Thomson Press.

Bailey, Trevor and Anthony Gatrell. 1995. Interactive Spatial Data Analysis. New York: Wiley.

Waller, Lance A. and Carol A. Gotway. 2004. Applied Spatial Statistics for Public Health Data. Wiley.

All of the relevant papers and workbooks at Luc Anselin's website (from University of West Virginia to University of Texas-Dallas to University of Illinois to Arizona State University) are generally referenced or required reading in my courses.

A few additional substantive sources for graduate students included:

Abbott, Andrew. 1997. "Of time and space: the contemporary relevance of the Chicago School." Social Forces 75 (4): 1149-1182.

C.J. Galpin. 1915. The Social Anatomy of a Rural Community. Research Bulletin No. 34. Wisconsin Agricultural Experiment Station.

Gieryn, Thomas F. 2000. "A space for place in sociology." Annual Review of Sociology Vol. 26: 463-496.

Luloff, A.E. and William A. Befort. 1989. "Land Use Change and Aerial Photography: Lessons for Applied Sociology." Rural Sociology 54 (1), 92105.

Park, Robert E. 1929. "Urbanization as measured by newspaper circulation." American Journal of Sociology 35 (1): 60-79.

Obviously, this is a lot of material but one could learn a lot from careful and meticulous study of just the original Galpin bulletin. As Lei Chen pointed out to me some years ago when taking this course: his work led to the Chicago School although they seem to have forgotten it.

$P R V: \quad$ Are there specific software packages or tools you feel are especially helpful in your teaching? For example, I take from your remarks that you believe good spatial data analysts need to understand and know how to use GIS tools, right?

FMH: I locate spatial analysis in its broadest sense as situated across the scientific data visualization and the spatial statistics bodies of knowledge. Data viz, as computer scientists call it, has blossomed along with the rise in desktop hardware and software. John Tukey taught us to "look" at our data as part of the analysis plan. Many of the concepts that I identified above can't be readily understand in tabular format but must be "seen" to be best understood. Thus, I do feel that a "good spatial data analyst" must at least be conversant in using GIS tools. I was fortunate to have access to the industry leading platform ArcView (at first) and ArcGIS from ESRI. However, I've always been an advocate of freeand-open-source (FOSS) software. While the GRASS platform was perhaps too complicated for beginners, the Quantum GIS (QGIS) package has a simpler interface, works with ESRI Shapefiles, and has an impressive array of user-built plugins (e.g., a real-time data link to the $\mathrm{R}$ program).

The GeoDa project led by Luc Anselin is the standard for much of the course work. It's free and actively updated (OpenGeoDa). And, unlike the previous version, GeoDa, OpenGeoDa is truly open-source.

Investing the time to learn the $\mathrm{R}$ program is worth it in the long run. Many beginners who cut their statistical teeth in SAS or SPSS or even Stata find $\mathrm{R}$ a complex maze of different approaches. They are right! But, like many complex things, it's because of the power that R's design yields. I recommend that beginners---or even old-timers like me---use one or more of the GUIs now available for R. John Fox's Rcmdr interface is much like the older SPSS point-and-click approach. It does data import from SPSS and other data formats, allows recodes of variables, and other data management activities as well as numerous analytical tools. A growing list of plugins for it are now available. Another GUI that I also use is Rstudio. It's billed as an "integrated development environment" (or IDE) but it's also 
a Stata-like interface for $\mathrm{R}$ and free.

If I can teach students to use relevant software that they can legally take with them, then they are prepared to continue learning without the need to come to some central laboratory where commercial software is available to them.

$P R V$ : As an $\mathrm{R}$ advocate, I certainly understand what you say about the R environment, It can be a difficult transition for sure. But what about resources on the internet? Any favorite websites you use when you teach?

FMH: Oh Yes! I am a big believer in students "playing" with sources through which to build their understanding and skill-sets. Here are a few but I maintained a running list of them during a semester since students would inevitably find new ones for me to look at too.

Center for Spatially Integrated Social Science

(http://www.csiss.org/)

Spatial Analysis Lab, Arizona State University

(https://geodacenter.asu.edu)

Luc Anselin

(http://geoplan.asu.edu/anselin)

Bradley P. Carlin

(http://www.biostat.umn.edu/ brad/)

Peter J. Diggle

(http://www.maths.lancs.ac.uk/ diggle/)

Stewart Fotheringham (http://www.st-

andrews.ac.uk/gsd/people/asf7/)

Andrew Lawson

(http://www.sph.sc.edu/alawson/default.htm)

Serge Rey

(http://http://geoplan.asu.edu/rey)

Peter Rogerson

(http://www.acsu.buffalo.edu/ rogerson/)

David M. Theobald

(http://www.nrel.colostate.edu/ davet/)

Census Bureau, Geography

(http://www.census.gov/geo/www/)

and most Federal agencies with published spatial data.

$P R V$ : That list will be helpful to readers of this journal. What preparatory skills or basic knowledge should graduate students bring to a course in spatial demography to ensure they get the most out of the course?

$F M H$ : It would be terribly frustrating for graduate students to jump into such a course in the first year. I've had advisors insist that their new GRA take the course, effectively expecting me to train them for their assistantships. It was always a miserable experience for the student. Having some experience with social statistics up through regression modeling is necessary. Having a course on research design, perhaps even survey methods, would be desirable. At Mississippi State, we required a first semester course on the management of social science data so that graduate students were prepared to actually manipulate data. You might guess, I helped start that course back in the late 1980 s when PCs were becoming more popular than using the mainframe available to us. Having experience with a conventional row-column data matrix is a must and some experience accessing data from the Internet using standard tools probably should be a requirement too.

$P R V$ : What's the proper balance between spatial theory, spatial concepts, GIS skills and formal spatial modeling methodologies in a graduatelevel spatial demography course?

FMH: For most of my career in teaching social statistics and research methods, I've been a strong proponent of theory-directed data analysis. If a course is taught with a methods focus, however, the major components are shown graphically below. (This was taken from one of my lectures.) These represent about equal proportions of time in a semester-length course for graduate students.

Most of the spatial concepts are contained in the GIS visualization and operations section. I feel that it is a fundamental to formally cover Census geography. I've seen too many poorly-merged spatial datasets with resulting "empty spaces" that just are ignored by the naïve researcher when a simple study of the Census Bureau's Geographic Areas Reference Manual would have saved the day. For instance, students should know in specific terms what are the differences between Census Places and Census Designated 
Places. (I read a colleague's publication which confused them in print so don't take this understanding for granted!) Moreover, about how many Census tracts were there in 2000? All this is to lead to the development of a gut sense of when your data are just not adding up.

The digital counterpart is the TIGER reference manual. I've actually given exams over the basic elements of the GARM and the TIGER Line files. I've done this not to be punitive but to reduce grief and personal distress when dissertation files are being questioned by advisory committee members and the student just doesn't know how to answer. Why? Because they simply did not have a basic understanding of these two standard databases. This isn't much different in principle than the preliminary exam questions asking whether Durkheim, Weber, or Marx were most likely to say that "men make their history but they do not make it just as they please but under circumstances encountered directly from the past" (my poor recollection of the Eighteenth Brumaire of Louis Napoleon). You get my point?

$P R V$ : Sure. But that's a very wide spectrum of knowledge. What about teachers? What preparation do you feel teachers of spatial demography need in order to offer a strong, wellgrounded course?

FMH: Well, I'd say they must be committed to the topic instead of just taking it on as a service style course. Ideally, a sabbatical leave spent in residence at a place where mentor-ship can take place would be good. Joe Francis at Cornell developed his course this way after I sent him my syllabus. But most faculty do not have that luxury. Instead try to attend one of the workshops taught by Anselin or through ICPSR's Summer Instruction Program. Find a peer or two either on campus or off to ask those questions that anyone will have in learning a new specialty. Join a listerv on the topic.

They must be able to produce reasonable quality maps using all types of spatial data using a known GIS software package (ArcGIS is preferable but QGIS isn't bad). They must have a firm grasp of Census geography and what is in TIGER. Using
TIGER files from the Bureau is a must. Knowing how to geocode address data is important, especially the foibles in this set of procedures. Understanding exploratory spatial data analysis (ESDA) is a must but Anselin has online videos illustrating the concepts involved available through the GeoDa Center. Having a good sense of what demography processes lend themselves to what form of visualization and analysis will be key since students will pepper you with these kinds of questions! Finally, extending your regression skill-set to basic spatial regression models using OpenGeoDa or the Spdep package in $\mathrm{R}$ would be important.

$P R V$ : Ah, yes... listserv resources. They weren't there when you and I got our start. How do you view the direction of our field? What should teachers of spatial demography be doing now to remain current and prepared for the future?

$F M H$ : Become part of the spatial demography community! I hope that the journal Spatial Demography through it's Forum area will become a place where continuing education is strongly supported. Be sure to order books for the library since acquisition librarians may miss some of these titles. If there are sufficient numbers at your institution, start a spatial demography study group. But, above all, do not be shy with questions. Finally, stay abreast of the websites of the knowledge-producers in the field so that new innovations can be identified. We hope that SD will facilitate that but we editors can't do it alone.

$P R V: \quad$ Do you have any specific advice for someone planning to teach spatial demography for the first time?

$F M H:$ Be aware of the "it's not sociology (or demography)" argument. I think that is not nearly as much the case now as it was back in the mid-1990s. But be committed to preparing classroom data examples which demonstrate the utility of the specialty for the rest of demography. Because of the explosion in "crime analysis," I had numerous criminology students in my courses. I also had forestry and public administration students. So be open to having a diverse student pool. They will bring different 


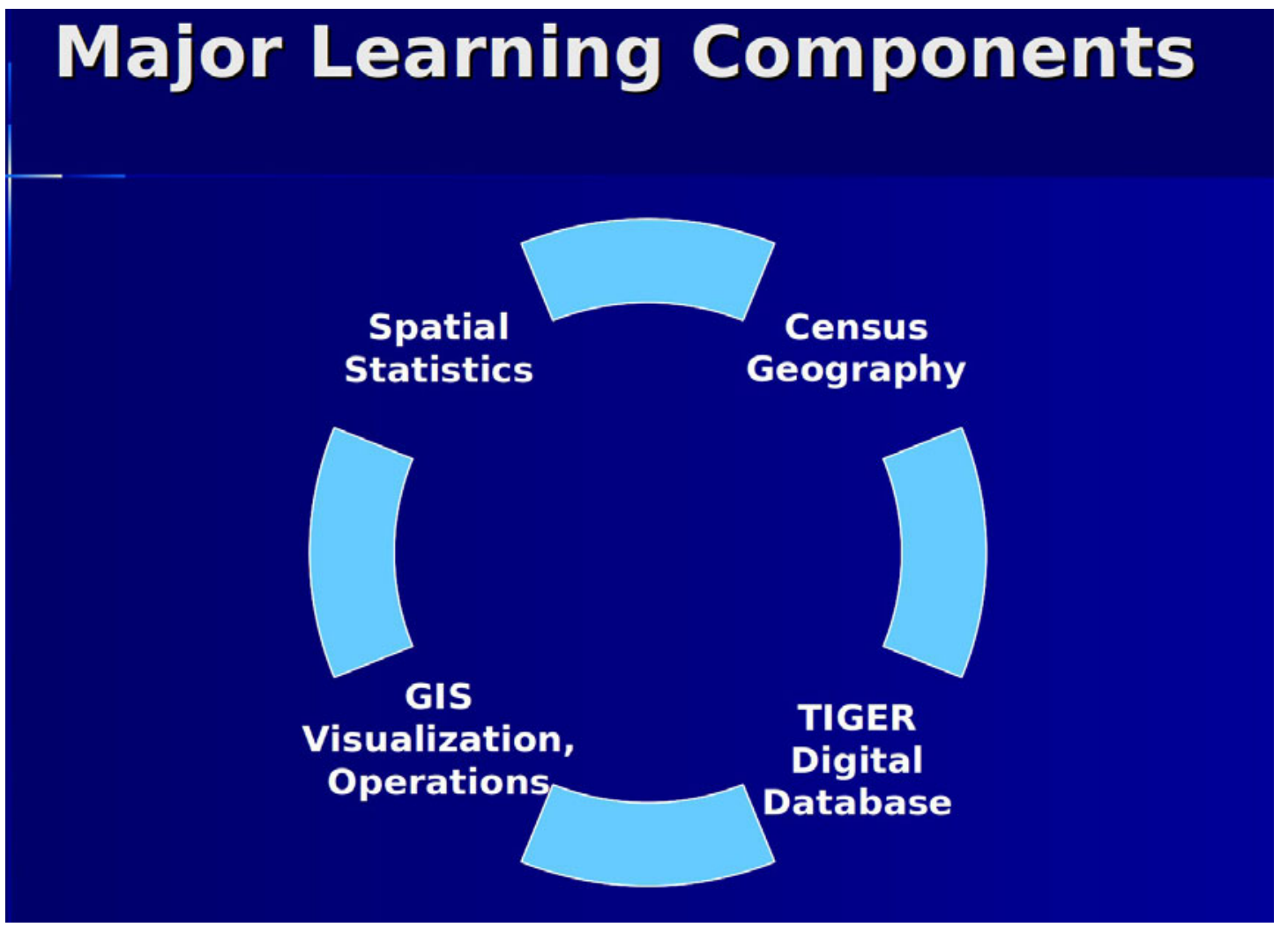

paradigms to the class but that will be a good thing from my experience.

Try to get computer lab support for the software you plan to use well ahead of time. Like the previous semester! Using open-source software tends to reduce the anxiety of IT personnel for installations but your mileage may vary.

Work the homework assignments yourself before making them available to students. Simple, but it does solve problems and potential embarrassment.

Try new things and tell the class when it's the first time for it. They will respect the candor and are likely to improve the assignment once they know what the purpose is. For instance, before crime data became widely available, I had a homework assignment to take crime listings with addresses published in a large newspaper in the state. Students were to build a dataset of this information and to geocode them to latitudelongitude coordinates, producing a point map over block group and county boundaries. I used only one week's worth of reports. One student got so excited that he went to the Library and keyedin a year's worth of crime reports for the metro area. He brought them back to class and shared them. That led to a conference paper among three students analyzing types of crime incidence by block-group long before this became somewhat commonplace. Lesson: look for interesting sources of data that are likely to be relevant to students enrolled in the course while keeping the general focus on spatial demography. And, the teacher will have fun, too.

$P R V: \quad$ As one of the Editors-in-Chief of this journal, how would you like to see the journal serve as a vehicle to effectively assist those involved in spatial demography instruction?

$F M H$ : Jeremy and I hope that it will serve as a significant catalyst around which those who teach in this area will flock. The sharing of ideas, class projects, course outlines, the good and not-sogood of a given textbook, will be critical to help 
the area mature. We welcome it and are open to innovative ideas through which to help the journal help them.

$P R V$ : What do you do when you're not involved in intellectual pursuits? Do you have any hobbies or recreations you'd like to share with readers?

FMH: Paul, after beating cancer that I contracted in 2005, I retired from MSU and took a job as Senior Policy Advisor at the Board of Regents Office in Atlanta. I spent about three years working there, using spatial demography to educate senior staff and Regents on how to better manage the exploding enrollment issues in Georgia. I'm a native and it was fun working in the Capital Walk area and teaching night courses at Emory as an Adjunct Professor. But I eventually tired of the long commute so I resigned my position at the Board Office and returned to Mississippi. My wife and I built a retirement home on a large lake north of Jackson, MS in the suburb of Ridgeland. We have family here and our son, a member of the PGA, is Director of Instruction at the Country Club of Jackson.

I play golf with Jon sparingly but really focus on my penchant for electronics. Since the age of eight, I've found radio waves and their propagation fascinating. About 10, a friend and I built a crystal radio out of a rusty Gillette razor blade, a coil of wire around a toilet paper tube and some wire for an antenna run up into a tree. We listened to the Georgia Tech vs. Vanderbilt football game but it could just as well have been of Neil Armstrong landing on the moon! I learned what a correlation coefficient was when I was about 12 years old, when winding an inductance coil for another project.

In the corner of my second floor office here at home, my amateur radio station is located in some custom cabinetry I had installed during the building of our house. I have PVC pipes running inside walls containing cables to reach my antennas and ground system. We live in an HOA neighborhood but no one sees my antennas since one looks like a vent pipe emerging through the roof, another is a wire running just under the edge of the roof shingles, a third is inside of a bird house on a post in our small courtyard, and the forth in in the attic. I talk to people all over the world and have met some wonderful people. I was on the Board of Directors of the Jackson Amateur Radio Club and a staff member of the American Radio Relay League as Assistant Director of the Delta Division. So I do some bureaucratic stuff in these volunteer groups to further the hobby and promote emergency communications when needed.

Using an electronics workbench area located off of our garage, I also do some electronics design engineering and consult with the largest amateur radio manufacturing company in the U.S. which is located in Starkville, MS. Three products are in $\mathrm{R} \& \mathrm{D}$ at the moment. Two are directional high frequency antennas for portable operations by amateur radio operators. They are lightweight and breakdown into a nylon bag for easy transport. The third is a "mesh" of portable nodes for establishing private and encrypted communication systems in times of emergency, such as a hurricane, tornado, or flood. This system will allow amateur radio operators who work in emergency communications the capability to give telephone, e-mail, Internet access, and other tools when all other communications modes are out. These mesh nodes can also connect to personal cell phones since they will also operate over common WiFi frequency channels (2.4 gigahertz). I'm working with a programmer on the prospects of an app for iPhone and Android smartphones which would automatically connect an individual's phone to these mesh nodes and allow rescue information such as GPS coordinates to be obtained from those trapped or injured.

We enjoy being retired and the ability to visit with family and neighbors in a boating community. Taking a pontoon boat to breakfast early in the morning as the ducks, turtles, and alligators begin their day can be a blast. As I told a high school friend on the LSU Medical School faculty who said I didn't sound retired to him: I'm retired, not dead!

$P R V: \quad$ Thanks, Frank! Isn't retirement wonderful? 